\title{
Hypofractioned Radiation Therapy in the Treatment of Partial Breast: 30 Gy in Five Consecutive Fractions
}

\author{
Sara Terenzi, Rosaria Barbarino, Maria Daniela Falco, Daniela di Cristino, Luana Di Murro, \\ Dania Janniello, Gianluca Ingrosso, Alessandra Murgia, Grazia Tortorelli, Barbara Tolu, \\ Riccardo Santoni
}

Department of Diagnostic Imaging, Molecular Imaging, Interventional Radiology and Radiotherapy, Tor Vergata University General Hospital, Viale Oxford, Rome, Italy.

Email: sara_terenzi@fastwebnet.it

Received September $13^{\text {th }}$, 2012; revised October $12^{\text {th }}$, 2012; accepted October $24^{\text {th }}, 2012$

\begin{abstract}
Background and Purpose: Recent prospective studies have explored the partial breast irradiation (PBI) for patients with early-stage breast cancer using different technical approaches. The purpose of this study is to explore feasibility, tumor control and acute and late toxicity of a specific hypo-fractionated 3D-CRT when treating postmenopausal patients with early breast cancer with partial breast irradiation, using five fractions in five consecutive days. Materials and Methods: Ten patients, aged $\geq 70$ underwent breast conservative surgery for invasive breast carcinoma with a complete microscopic resection; no lymphovascular invasion was found and negative axillary node status was assessed. Metal clips were positioned in the surgical bed at the time of surgery. All of the patients provided an informed consent for breast irradiation. Seven patients received Tamoxifen. Of the ten patients, five were treated for left breast disease, and five for right breast disease. The dose fractionation schedule was $3000 \mathrm{cGy}$ delivered to the isocenter in 5 fractions (600 cGy/fr) using $6 \mathrm{MV}$ photons. According to the linear quadratic model and a $\alpha / \beta$ ratio of $4 \mathrm{~Gy}$ this prescription is equivalent to 50 Gy in a standard 2-Gy fractionation schedule. Patients were treated in the supine position. A comercial breast board was used as immobilization device in order to keep the arms of the patient raised. The clinical target volume (CTV) was drawn with a uniform 1-cm three-dimensional margin around the surgical clips. The CTV was limited to $3 \mathrm{~mm}$ from the skin surface and $3 \mathrm{~mm}$ from the lung-chest wall interface. A three-dimensional margin was added to the CTV to obtain the planning target volume (PTV). The ipsilateral and controlateral breast, the ipsilateral and controlateral lung, heart and spinal cord were contoured as organs at risk (OAR). The treatment was developed using Precise Plan Treatment Planning System and four no-coplanar fields. The constraints used have been: uninvolved breast (ipsilateral breast-PTV): $\mathrm{V}_{15} \leq 50 \%$; heart: $\mathrm{V}_{3} \leq 10 \%$; ipsilateral lung: $\mathrm{V}_{10} \leq 20 \%$; controlateral lung: $\mathrm{V}_{5} \leq 10 \%$ and controlateral breast: maximum dose $\leq 1 \mathrm{~Gy}$. We required PTV coverage of $\geq 90 \%$. Patient set-up was verified every day before treatment using portal images. No tumour bed boost was delivered. Clinical assessments of early normal tissue reaction were carried out every day during radiotherapy and 10 days after the end of the treatment. After radiotherapy, we visited all patients every 3 months during the first 2 years and every six month thereafter. Frontal and lateral pictures of the breast were taken on the first day of treatment (baseline), at the end of treatment, 10 days after the end of treatment and at the first follow-up. Any change in breast appearance compared with the baseline picture was scored on a four-point RTOG for acute and late radiation morbidity scoring scale. Results: No local or distant recurrences were observed and then confirmed by mammograms performed every year and breast ultrasound performed every six months. For acute and late toxicity, only 2 patients developed acute effects at the end of the treatment. Conclusion: The clinical outcomes observed in ten patients demonstrate a good feasibility of the schedule adopted both in terms of tumour control and acute and late toxicity, with good cosmetics results. Long term follow-up and a large number of patients will be needed for full evaluation.
\end{abstract}

Keywords: Breast Cancer; Partial Breast Irradiation; Hypofractioned

\section{Introduction}

In the past decades, a major change has occurred in the local management of breast cancer, from a mutilating therapeutic approach to a conservative approach with osmetic and functional aims. The use of conservative surgery combined with whole-breast irradiation has been established as a valid alternative to mastectomy. The 
conservative approach consists in the removal of the tumor, followed by 5 - 7 weeks of daily whole breast irradiation (total dose of 50 Gy delivered to the entire breast and 10 - 16 Gy boost delivered to the tumor bed). A disadvantage of this approach is the increase of the nonbreast-cancer-related morbidity due to irradiation of nontarget tissue $[1,2]$ and the prolonged duration of treatment.

Observation from earlier studies demonstrated that distant recurrences, in quadrants other than that originnally involved by the tumour, occur infrequently (range, $0.6 \%-6 \%$ ) [3-13].

A strategy that aims at improving the therapeutic ratio and at reducing treatment duration, in women with relatively low risk of local tumour relapse, involves limited high-radiation doses to the index quadrant and reduces doses to breast tissue remote from the tumour bed $[14,15]$. Radiobiological analysis of clinical data has shown that breast adenocarcinomas have an $\alpha / \beta$ ratio of $4 \mathrm{~Gy}$, like late reacting normal tissues. Consequently, hypo-fractionation in breast cancer may have a reasonable radiobiological support. Recent prospective studies have thus explored the techniques of only treating the tumor bed of the breast, i.e. partial breast irradiation (PBI), for patients with early-stage breast cancer using different technical approaches [16-24]. These studies have investigated the use of low-dose-rate and high-doserate brachytherapy and the use of External-Beam Radiotherapy (EBRT) for partial breast irradiation.

The purpose of this study is to evaluate feasibility, tumor control and acute and late toxicity of a specific hypo-fractionated 3D-CRT in the treatment of partial breast in postmenopausal patients with early breast cancer, using five consecutive 6 Gy fractions.

\section{Material and Methods}

\subsection{Patients}

Sarting on January 2008 ten patients, out of all those who underwent breast conservative surgery for invasive breast carcinoma, received postoperative radiotherapy delivered to the index quadrant only after having provided full written informed consent. The inclusion criteria are listed in Table 1. All of the patients enrolled in the study were in postmenopausal status, age ranged from 70 to 84 years (median 76 years). Eight patients had Stage I invasive ductal carcinoma and two patients had Stage I invasive lobular carcinoma. Tumour size ranged between $10 \mathrm{~mm}$ and $20 \mathrm{~mm}$, with a median of $14 \mathrm{~mm}$. Seven patients had positive estrogenic receptors and received Tamoxifen, no patients received chemotherapy. All patients underwent lumpectomy with negative surgical margins. The surgeons were requested to place clips at the borders of the surgical bed, using a minimum of six clips. The presence of surgical clips represented a selection criteria to avoid geographic misses. Of the ten patients, five were treated for left breast disease, and five for right breast disease. The main patients' characteristics are listed in Table 2. Clinical assessments of early normal tissue reaction were carried out every day during radiotherapy and after 10 days from the end of the treatment. After radiotherapy, all of the patients underwent a clinical examination every 3 months during the first two years and every six months subsequently. Median follow-up from the end of irradiation was 21.1 months (range, 10 - 48 months).

Bilateral mammogram, and bilateral breast ultrasound were obtained once a year during follow-up. An echocardiogram was obtained in patients with left breast cancer. Frontal and lateral pictures (depending on the tumour

Table 1. Inclusion criteria.

\begin{tabular}{|c|c|}
\hline \multicolumn{2}{|l|}{ Age $>70$ aа } \\
\hline \multicolumn{2}{|l|}{ Patological stage pT1 pN0 } \\
\hline \multicolumn{2}{|c|}{ Surgical margin negative (>2 mm) } \\
\hline \multicolumn{2}{|l|}{ Clips placed in tumor bed } \\
\hline \multicolumn{2}{|c|}{ Full informed consent from patient } \\
\hline \multicolumn{2}{|l|}{ No lymphovascular invasion } \\
\hline \multicolumn{2}{|l|}{ Unifocal } \\
\hline \multicolumn{2}{|c|}{ Intraductal component $<25 \%$} \\
\hline \multicolumn{2}{|l|}{ ER and PgR positive } \\
\hline \multicolumn{2}{|c|}{ ER = Esrogen Receptor; PgR = Progesteron Receptor } \\
\hline \multicolumn{2}{|c|}{ Table 2. Baseline patient characteristics $(n=10)$. } \\
\hline Characteristics & Patients \\
\hline Breast side & \# \\
\hline Right & 5 \\
\hline Left & 5 \\
\hline Tumor estrogen receptor status & \# \\
\hline Positive & 10 \\
\hline Negative & 0 \\
\hline Tumor progesterone receptor status & \# \\
\hline Positive & 10 \\
\hline Negative & 0 \\
\hline Tumor Her-2 status & \# \\
\hline Score 0 & 3 \\
\hline Score 1 & 2 \\
\hline Score 2 & 2 \\
\hline Score 3 & 1 \\
\hline Unknown & 2 \\
\hline
\end{tabular}


site) of the breast were taken on the first day of treatment (baseline), at the end of the treatment, after 10 days from the end of the treatment and at the first follow-up visit (Figure 1). Any changes in breast appearance were compared with the baseline picture and was scored on a fourpoint RTOG for acute and late radiation morbidity scoring scale.

\subsection{Patient Positioning and Image Acquisition}

Patients underwent Computed Tomography (CT) imaging in supine position with a commercial breast board immobilization device in order to keep their arms raised. CT scanning was performed with a $0.5 \mathrm{~cm}$ scan spacing. The scans extended to completely cover the involved breast, lungs, and a $5 \mathrm{~cm}$ margin in the cranial and caudal directions.

\subsection{Treatment Planning}

The prescribed dose to the $95 \%$ isodose was 3000 cGy in 5 fractions (600 cGy/fr) in 5 consecutive days. All patients were treated in the supine position. The treatment was developed using Precise Plan Treatment Planning System $^{\circledR}$ (Elekta, Crowley, United Kingdom) and four no-coplanar $6 \mathrm{MV}$ photon fields were used (Elekta Precise ${ }^{\circledR}$ Linear Accelerator, Crawley, United Kingdom).

The planning volumes were defined as follows: the gross target volume (GTV) was contoured on the surgical clips placed during surgery, the clinical target volume (CTV) was draobtained with a uniform $1 \mathrm{~cm}$ three dimensional margin around the surgical clips (GTV) and

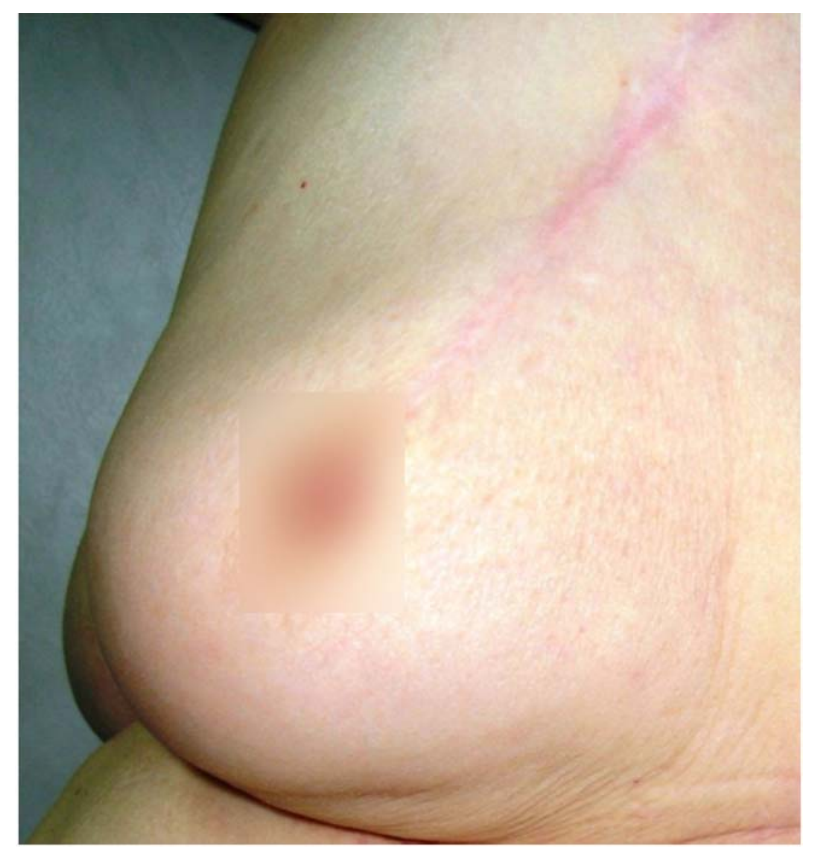

Figure 1. Photo captured 12 month after the end of radiotherapy. the planning target volume (PTV) was defined as the CTV plus a uniform $1 \mathrm{~cm}$ three dimensional margin. The PTV was limited to $3 \mathrm{~mm}$ from the skin surface and 3 $\mathrm{mm}$ from the lung-chest wall interface. As organ at risk (OAR) we considered the ipsilateral and contralateral breast, the ipsilateral and controateral lung and the heart. The heart was contoured from the first CT slice below the pulmonary artery to the apex inferiorly. Both lungs were contoured in their entirety (Figure 2).

The constraints used are listed in Table 3. Less than $20 \%$ of the ipsilateral lung had to receive $30 \%$ of the prescribed dose $\left(\mathrm{V}_{10} \leq 20 \%\right)$; less than $10 \%$ of the contralateral lung had to receive $15 \%$ of the prescribed dose $\left(\mathrm{V}_{5} \leq 10 \%\right)$; less than $10 \%$ of the contoured heart volume had to receive $10 \%$ of the prescribed dose $\left(V_{3} \leq 10 \%\right)$; maximum dose to the controlateral breast was $<1 \mathrm{~Gy}$. We also attempted to maintain the $50 \%$ volume of the ipsilateral breast (IB) minus planning target volume (PTV) (IB-PTV), to receive less than 50\% (15 Gy) of the prescribed dose. Patient set-up was verified every day

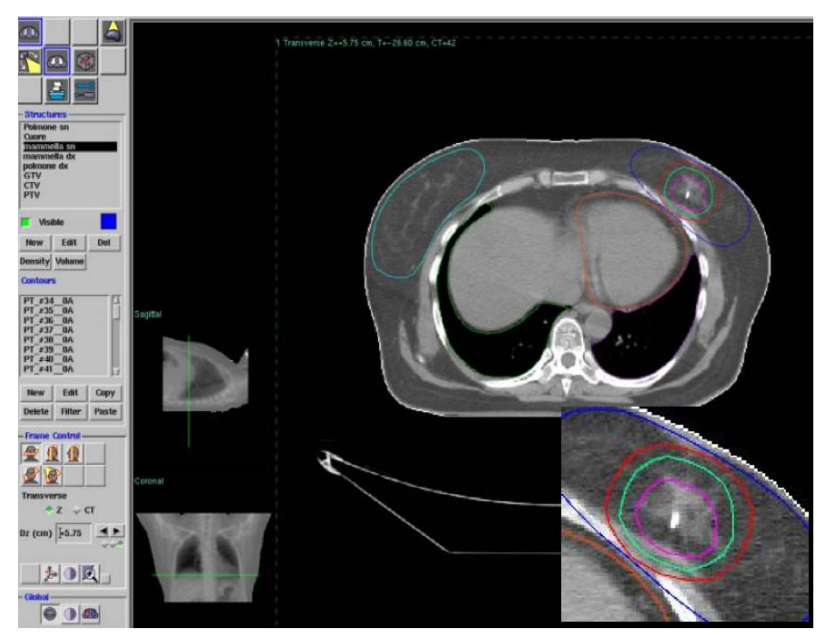

Figure 2. Target and organ at risk (OAR) conturing. Pink is the Gross Tumor Volume (GTV); Light green is the Clinical Target Volume (CTV); Red is the Planning Target Volume (PTV); Blue is the ipsilateral breast; Cyan is the controlateral breast; Orange is the heart; Violet is the ipsilateral lung; Green is the controlateral lung.

Table 3. Constraints for OAR.

\begin{tabular}{lc}
\hline OAR & Constraints \\
\hline Ipsilateral Lung & $\mathrm{V}_{10}<20 \%$ \\
Controlateral Lung & $\mathrm{V}_{5}<10 \%$ \\
Heart & $\mathrm{V}_{3}<10 \%$ \\
Ipsilateral Breast-PTV & $\mathrm{V}_{15}<50 \%$ \\
Controlateral Breast & $<1 \mathrm{~Gy}$ \\
OAR = organs at risk; PTV = planning target volume
\end{tabular}


before treatment, using orthogonal portal images (Gantry $0^{\circ}$ and $90^{\circ}$, coach $0^{\circ}$ ) and 2 portal images of the treatment beams.

\section{Results}

The target coverage was acceptable for all patients. The dose-volume constraints of OARs were always respected. Only in 1 patient the uninvolved breast dose-volume constraint was not respected given that the $82 \%$ of uninvolved breast volume received more than 15 Gy (Table 4). This was probably due to the anatomic position of the tumour (supero-internal quadrant) and to the small volume of the breast (435 cc).

We observed grade 1 acute skin toxicity (Radiation Therapy Oncology Group scale) developing during the first week after the end of treatment in 2 patients (20\%). No patients had late skin toxicity. No difference was observed between patient who received or not Tamoxifen. No patients experienced a reduction in left ventricular ejection fraction or in forced expiratory volume. To date no local recurrence was observed.

\section{Discussion}

In the far past years the treatment for breast cancer was mastectomy while actually the gold standard for patients with early-stage breast cancer is conservative with a cosmetic and functional surgical approach followed by radiotherapy to increase local control and overall survival [25]. The standard radiation therapy treatment has a duration of 5 - 7 weeks and the delivered dose is $50 \mathrm{~Gy}$ in 25 daily fractions delivered to the entire breast plus 10 Gy boost to the tumour bed. This approach has the disadvantage of prolonged duration, which can be a serious inconvenience for patients that have to travel every day for a prolonged period to the radiation therapy centre, especially for the elderly ones. Several clinical trials have demonstrated that shorter radiation schedules, justified by radiobiological models, delivering larger doses per fraction in shorter periods of time [26-30] offer equivalent local control and same acute and late toxicity compared to the standard radiation therapy courses. Whelan et al. [27] examined whether a 22-day radiation therapy fractionation schedule was as effective, on the local control, as the traditional 35-day schedule in 1934 women with invasive breast cancer who underwent BCS with pathologically clear resection margins and negative axillary lymph nodes. Patients were randomly assigned to receive $42.5 \mathrm{~Gy}$ in 16 fraction over 22 days or $50 \mathrm{~Gy}$ in 25 fraction over 35 days to the whole breast. With a median follow-up of 12 years no differences in local recurences, disease free or overall survival rates and cosmetic results were recorded. They concluded that the more convenient 22-day fractionation schedule appear to be an acceptable alternative to the 35-day schedule. The START A (Standardization of Breast Radiotherapy) from the UK trial has shown that 41.6 Gy in 13 fractions or 39 Gy in 13 fractions are similar to the standard treatment (50 Gy in 25 fractions) in terms of local-regional tumour control and late normal tissue effects [28]; this results are consistent with those of the START B trial, which has shown that a radiation schedule of $40 \mathrm{~Gy}$ in 15 fractions offers equivalent results to the standard schedule of 50 Gy in 25 fractions [29]. Livi et al. [30] evaluated the incidence of loco-regional recurrence and the cosmetic results in a group of 539 patients with breast cancer treated with a hypo-fractionated schedule after conservative surgery. The dose delivered was $44 \mathrm{~Gy}$ (2.75 daily fraction) and the tumour bed boost was $10 \mathrm{~Gy}$ (Electron beam). They obtained a low local relapse and good tolerance $(76.4 \%$ patients showing grade 0 - 1 late toxicity, $20.9 \%$ patients grade 2 and $2.5 \%$ patients grade 3 ; no patients with grade 4 toxicity was observed). All this fraction regimen do not represent the limits of hypofractionation for whole breast radiotherapy. The UK FAST trial [31] randomized 915 women 50 years old or older with node-negative tumours, following breast conservative surgery, to receive whole breast radiotherapy delivered using 3D dosimetry to a total dose of $50 \mathrm{~Gy}$ in 25 fractions (control) versus 28.5 Gy or 30 Gy in 5 onceweekly fractions of $5.7 \mathrm{~Gy}$ or $6.0 \mathrm{~Gy}$ with no tumour bed boost. The first analysis showed good results in terms of late normal tissue responses and tumour control. A schedule of $30 \mathrm{~Gy}$ in 5 fractions over 15 days to the

Table 4. DVH analysis: OAR doses.

\begin{tabular}{ccccccccccccc}
\hline OAR & Patient & Patient & Patient & Patient & Patient & Patient & Patient & Patient & Patient & Patient \\
& $\mathbf{1}$ & $\mathbf{2}$ & $\mathbf{3}$ & $\mathbf{4}$ & $\mathbf{5}$ & $\mathbf{6}$ & $\mathbf{7}$ & $\mathbf{8}$ & $\mathbf{9}$ & $\mathbf{1 0}$ \\
\hline Hearth: dose to 10\% volume & $0.5 \mathrm{~Gy}$ & $1 \mathrm{~Gy}$ & $0.5 \mathrm{~Gy}$ & $1 \mathrm{~Gy}$ & $2 \mathrm{~Gy}$ & $0.5 \mathrm{~Gy}$ & $1 \mathrm{~Gy}$ & $0.1 \mathrm{~Gy}$ & $1 \mathrm{~Gy}$ & $1 \mathrm{~Gy}$ \\
Ipsilateral Lung: dose to 20\% volume & $1 \mathrm{~Gy}$ & $4 \mathrm{~Gy}$ & $2 \mathrm{~Gy}$ & $1.5 \mathrm{~Gy}$ & $4 \mathrm{~Gy}$ & $1 \mathrm{~Gy}$ & $2 \mathrm{~Gy}$ & $1 \mathrm{~Gy}$ & $1 \mathrm{~Gy}$ & $2 \mathrm{~Gy}$ \\
Controlateral Lung: dose to $10 \%$ volume & $0.1 \mathrm{~Gy}$ & $0.4 \mathrm{~Gy}$ & $0.1 \mathrm{~Gy}$ & $0.1 \mathrm{~Gy}$ & $1 \mathrm{~Gy}$ & $0.1 \mathrm{~Gy}$ & $0.1 \mathrm{~Gy}$ & $0.1 \mathrm{~Gy}$ & $0.1 \mathrm{~Gy}$ & $0.1 \mathrm{~Gy}$ \\
Controlateral Breast: dose to whole organ & $0.2 \mathrm{~Gy}$ & $0.6 \mathrm{~Gy}$ & $0.5 \mathrm{~Gy}$ & $0.1 \mathrm{~Gy}$ & $0.9 \mathrm{~Gy}$ & $0.1 \mathrm{~Gy}$ & $0.1 \mathrm{~Gy}$ & $0.1 \mathrm{~Gy}$ & $0.1 \mathrm{~Gy}$ & $0.3 \mathrm{~Gy}$ \\
Ipsilateral Breast-PTV: dose to 50\% volume & $4.5 \mathrm{~Gy}$ & $4 \mathrm{~Gy}$ & $27 \mathrm{~Gy}$ & $10 \mathrm{~Gy}$ & $7 \mathrm{~Gy}$ & $12 \mathrm{~Gy}$ & $14 \mathrm{~Gy}$ & $5 \mathrm{~Gy}$ & $6 \mathrm{~Gy}$ & $10 \mathrm{~Gy}$ \\
\hline
\end{tabular}

$\mathrm{DVH}=$ dose-volume histogram; OAR = organ at risk. 
whole breast, using 3D dosimetry, reported very mild acute reactions and acceptable 2-year outcome in terms of change in breast appearance compared to a matched sample of patients treated to $50 \mathrm{~Gy}$ in 25 fractions [32].

Observations that the vast majority of ipsilateral breast recurrences occur in close proximity to the lumpectomy cavity have led to question the opportunity of elective partial breast irradiation (PBI), treating only the tumor bed. Baglan KL et al. [21] presented a 3D-CRT technique for partial breast irradiation in supine position. The prescribed dose was $34 \mathrm{~Gy}$ in 5 patients and 38.5 Gy in 4 patients, delivered in 10 fractions twice daily over 5 consecutive days. They reported an excellent patient tolerance with minimal acute toxicity. No skin changes were noted during treatment, and at the initial 4 - 8-week follow-up examination, only mild localized hyperpigmentation and/or erythema were observed. Formenti S. et al. [22] reported the clinical and dose-volume histogram results in 47 patients accrued to a 3D-CRT accelerated partial breast irradiation (APBI) protocol in the prone position. The prescribed dose was $30 \mathrm{~Gy}$ at $6 \mathrm{~Gy} /$ fraction delivered in 5 fractions within 10 days. The lung and the heart were spared by treating in the prone position. Acute toxicity was mild (Grade 1 - 2 erythema). With a median follow-up of 18 month only grade 1 late toxicity occurred, and no patient developed local recurrence. Livi L. et al. [23] compared, in a randomized phase III clinical trial, conventional (tangential field) fractionated whole breast treatment (Arm A, 128 patients) with accelerated partial breast irradiation plus intensity-modulated radiotherapy (Arm B, 131 patients). For patients in Arm B (PBI) the prescribed dose was $30 \mathrm{~Gy}$ in 5 fractions, $6 \mathrm{~Gy} /$ fraction. The rate of Grade 1 and Grade 2 acute skin toxicity was respectively 22\% and 19\% in Arm A (Radiation Therapy Oncology Group scale). The tolerance in Arm B was excellent with only 5\% Grade 1 and $0.8 \%$ Grade 2 acute skin toxicity. With a median 9.6 years of follow-up Antonucci et al. [24] compared a group of patients treated with APBI vs a similar group of patients treated with whole breast irradiation to determine the potential differences in local recurrence rates according to the volume breast tissue irradiated. The cumulative incidence of ipsilateral breast tumour recurrences at 10 years was $5 \%$. On matched-pair analysis, the rate of ipsilateral breast tumour recurrences was not significantly statistically different between the patient groups. These data suggest the potential efficacy of APBI in selected low-risk patients. Different studies [33-38] demonstrate that breast cancer has the same radiobiological behaviour of late reacting normal tissue ( $\alpha / \beta$ ratio of $4 \mathrm{~Gy}$ ), late effects (fibrosis and telangiectasia) have $\alpha / \beta$ ratio of $2 \mathrm{~Gy}$ and 4 Gy respectively, and acute reaction (erythema and desquamation) 8 Gy and 11 Gy respectively. To compare the fractionation schedule of 30 Gy delivered in 5 consecu- tive days with the conventional fractionation of 50 Gy delivered in 32 days, the Biologically Effective Dose (BEDs) has to be calculated assuming cell repopulation during treatment. The BEDs formula taking into account cell repopulation is the follow:

$$
\mathrm{BED}=n d[1+d /(\alpha / \beta)]-\left[\ln 2 /\left(\alpha T_{p o t}\right)\left(T-T_{k}\right)\right] .
$$

were $n$ is the number of fraction, $d$ is the dose per fraction, $\alpha / \beta$ is a tissue-specific and effect-specific parameter associated with the linear-quadratic model, $T$ is the overall time of radiotherapy (days, with first day counted as day 0$), T_{k}$ is the Kick-off time of repopulation in the tissue of interest (21 days) [26,39,40], $\alpha$ is the radiosensitivity coefficient of non recoverable damage (0.35) [34, 41] and $T_{p o t}$ is the potential doubling time of cancer repopulation cells (3 days) [42,43]. This correction for cell proliferation causes the tumour standard treatment BED values to decrease by $3 \mathrm{~Gy}$ (from $75 \mathrm{~Gy}$ to $72 \mathrm{~Gy}$ ). The BED values of PBI schedule were calculated with the standard equation:

$$
\mathrm{BED}=n d[1+d /(\alpha / \beta)] .
$$

considering that the treatment is accomplished within a period that is shorter than the lag period. Table 5 lists the BEDs for tumour control, the early responses (erythema and desquamation), and the late responses (telangiectasia and fibrosis). The BEDs for normal tissue acute effects were generally lower for the $30 \mathrm{~Gy}$ hypo-fractionated schedule than for the standard 50 Gy treatment, indicating that the risk of radiation-induced complications should be lower in the PBI schedule.

According with the literature experience [22,23,31,32] and to our very preliminary results we want to increase our experience of a $30 \mathrm{~Gy}$ (6 Gy/fraction) fractionation schedule delivered in 5 consecutive days, with threedimensional conformal radiotherapy (3D-CRT), without considering an intermediate time period in order to have a complete cellular recovery between fractions ( $>24 \mathrm{~h})$. The proposal of such a simpler and less expensive technique, compared to Intensity Modulated Radiotherapy

\begin{tabular}{|c|c|c|c|}
\hline & $\alpha / \beta$ (Gy) & $\begin{array}{c}\text { Standard } \\
(50 \mathrm{~Gy})\end{array}$ & $\begin{array}{c}\text { Hypofractionated } \\
\text { (30 Gy) }\end{array}$ \\
\hline Erythema & 8 & 63 & 53 \\
\hline Desquamation & 11 & 59 & 46 \\
\hline Teleangectasia & 4 & 75 & 75 \\
\hline Fibrosis & 2 & 100 & 120 \\
\hline Tumor & 4 & 75 & 75 \\
\hline Tumor $^{*}$ & 4 & 72 & 75 \\
\hline
\end{tabular}

Table 5. Biologically effective doses (BED).

*Taking into account cell proliferation during course of treatment. 
(IMRT), with an excellent coverage of the target volume and excellent results in term of dose-volume histogram for OARs for all patients (Table 4), seems feseable but deserves more experience and long term results before beeing delivered to a larger population of patients.

\section{Conclusion}

The clinical results observed in ten patients demonstrated a good feasibility of the schedule adopted both in terms of tumour control rate and acute and late toxicity, with good cosmetics results. Encouraged by the protocol study of the University of Florence [23] (where the age inclusion criteria is $>40 \mathrm{y}$ ), we propose to go on with this study delivering this schedule to patients younger than 70 years in order to achieve a larger number experience.

\section{REFERENCES}

[1] M. Clarke, R. Collins, S. Darby, C. Davies, P. Elphinstone, E. Evans, et al., "Effects of Radiotherapy and of Differences in the Extent of Surgery for Early Breast Cancer on Local Recurrence and 15-Years Survival: An Overview of the Randomised Trials," Lancet, Vol. 366, No. 9503, 2005, pp. 2087-2106.

[2] S. C. Darby, P. McGale, C. W. Taylor and R. Peto, "Long-Term Mortality from Heart Disease and Lung Cancer after Radiotherapy for Early Breast Cancer: Prospective Cohort Study of about 300,000 Women in US SEER Cancer Registries,” Lancet Oncology, Vol. 6, 2005, pp. 557-565. doi:10.1016/S1470-2045(05)70251-5

[3] A. Fourquet, F. Campana, B. Zafrani, V. Mosseri, P. Vielh, J. C. Durand, et al., "Prognostic Factors of Breast Recurrence in the Conservative Management of Early Breast Cancer: A 25-Year Follow-Up,” International Journal of Radiation Oncology*Biology*Physics, Vol. 17, No. 4, 1989, pp. 719-725. doi:10.1016/0360-3016(89)90057-6

[4] J. Boyages, A. Recht, J. L. Connolly, S. J. Schnitt, R. Gelman, H. Kooy, et al., "Early Breast Cancer: Predictors of Breast Recurrence for Patients Treated with Conservative Surgery and Radiation Therapy," Radiotherapy \& Oncology, Vol. 19, No. 1, 1990, pp. 29-41. doi:10.1016/0167-8140(90)90163-Q

[5] J. M. Kurtz, J. M. Spitalier, R. Amalric, H. Brandone, Y. Ayme, J. Jacquemier, et al., "The Prognostic Significance of Late Local Recurrence after Breast-Conserving Therapy,” International Journal of Radiation Oncology*Biology*Physics, Vol. 18, No. 1, 1990, pp. 87-93. doi:10.1016/0360-3016(90)90271-K

[6] B. Fowble, L. J. Solin, D. J. Schultz, J. Rubenstein, R. L. Goodman et al., "Breast Recurrence Following Conservative Surgery and Radiation: Pattern of Failure, Prognosis, and Pathologic Findings from Mastectomy Specimens with Implications for Treatment," International Journal of Radiation Oncology*Biology*Physics, Vol. 19, 1990, pp. 833- 842.

[7] R. M. Clark, P. B. McCulloch, M. N. Levine, M. Lipa, R.
H. Wilkinson, L. J. Mahoney, et al., "Randomized Clinical Trial to Assess the Effectiveness of Breast Irradiation Following Lumpectomy and Axillary Dissection for Node Negative Breast Cancer,” Journal of the National Cancer Institute, Vol. 84, No. 9, 1992, pp. 683-689. doi:10.1093/jnci/84.9.683

[8] I. Gage, A. Recht, R. Gelman, A. J. Nixon, B. Silver, B. A. Bornstein, et al., "Long-Term Outcome Following Breast-Conserving Surgery and Radiation Therapy," International Journal of Radiation Oncology*Biology* Physics, Vol. 33, No. 2, 1995, pp. 245-251. doi:10.1016/0360-3016(95)02001-R

[9] G. Liljegren, L. Holmberg, J. Bergh, A. Lindgren, L. Tabár, H. Nordgren, et al., "10-Year Results after Sector Resection with or without Postoperative Radiotherapy for Stage I Breast Cancer: A Randomized Trial," Journal of Clinical Oncology, Vol. 17, No. 8, 1999, pp. 2326-2333.

[10] E. Touboul, L. Buffat, Y. Belkacémi, J. P. Lefranc, S. Uzan, P. Lhuillier, et al., "Local Recurrences and Distant Metastases after Breast-Conserving Surgery and Radiation Therapy for Early Breast Cancer," International Journal of Radiation Oncology*Biology*Physics, Vol. 43, No. 1, 1999, pp. 25-38. doi:10.1016/S0360-3016(98)00365-4

[11] T. E. Smith, D. Lee, B. C. Turner, D. Carter and B. G. Haffty, "True Recurrence vs New Primary Ipsilateral Breast Tumor Relapse: An Analysis of Clinical and Pathologic Differences and Their Implications in Natural History, Prognosis, and Therapeutic Management," International Journal of Radiation Oncology*Biology* Physics, Vol. 48, No. 5, 2000, pp. 1281-1289. doi:10.1016/S0360-3016(00)01378-X

[12] U. Veronesi, E. Marubini, L. Mariani, V. Galimberti, A. Luini, P. Veronesi, et al., "Radiotherapy after BreastConserving Surgery in Small Breast Carcinoma: LongTerm Results of Randomized Trial,” Annals of Oncology, Vol. 12, No. 7, 2001, pp. 997-1003. doi:10.1023/A:1011136326943

[13] E. Huang, T. A. Buchholz, F. Meric, S. Krishnamurthy, N. Q. Mirza, F. C. Ames, et al., "Classifying Local Disease Recurrences after Breast Conservation Therapy Based on Location and Histology: New Primary Tumors Have More Favorable Outcomes than True Local Disease Recurrences,” Cancer, Vol. 95, No. 10, 2002, pp. 2059-2067. doi:10.1002/cncr.10952

[14] J. M. Kurtz, R. Amalric, H. Brandone, Y. Ayme, J. Jacquemier, J. C. Pietra, et al., "Local Recurrence after Breast-Conserving Surgery and Radiotherapy. Frequency, Time Course, and Prognosis,” Cancer, Vol. 63, No. 10, 1989, pp. 1912-1917. doi:10.1002/1097-0142(19890515)63:10<1912::AID-CN CR2820631007>3.0.CO;2-Y

[15] T. E. Smith, D. Lee, B. C. Turner, D. Carter, B. G. Haffty, “True Recurrence vs New Primary Ipsilateral Breast Tumor Relapse: An Analysis of Clinical and Pathologic Differences and Their Implications in Natural History, Prognoses, and Therapeutic Management,” International Journal of Radiation Oncology*Biology*Physics, Vol. 48, 2000, pp. 1281-1289.

doi:10.1016/S0360-3016(00)01378-X 
[16] L. Cionini, P. Pacini and S. Marzano, "Exclusive Brachytherapy after Conservative Surgery in Cancer of the Breast,” Lyon Chirurgical, Vol. 89, 1993, p. 128.

[17] L. Krishnan, W. R. Jewell, O. W. Tawfik and E. C. Krishnan, "Breast Conservation Therapy with Tumor Bed Irradiation Alone in a Selected Group of Patients with Stage I Breast Cancer,” Breast Journal, Vol. 7, No. 2, 2001, pp. 91-96. doi:10.1046/j.1524-4741.2001.007002091.X

[18] F. A. Vicini, K. L. Baglan, L. L. Kestin, C. Mitchell, P. Y. Chen, R. C. Frazier, et al., "Accelerated Treatment of Breast Cancer,” Journal of Clinical Oncology, Vol. 19, No. 7, 2001, pp. 1993-2001.

[19] D. W. Arthur, D. Koo, R. D. Zwicker, S. Tong, H. D. Bear, B. J. Kaplan, et al., "Partial Breast Brachytherapy after Lumpectomy: Low-Dose-Rate and High-Dose-Rate Experience," International Journal of Radiation Oncology*Biology*Physics, Vol. 56, No. 3, 2003, pp. 681-689. doi:10.1016/S0360-3016(03)00120-2

[20] C. Leonard, D. Carter, J. Kercher, K. Howell, P. Henkenberns, M. Tallhamer, et al., "Prospective Trial of Accelerated Partial Breast Intensity-Modulated Radiotheratpy," International Journal of Radiation Oncology*Biology*Physics, Vol. 67, No. 5, 2007, pp. 1291-1298. doi:10.1016/j.ijrobp.2006.11.016

[21] K. L. Baglan, M. B. Sharpe, D. Jaffray, R. C. Frazier, J. Fayad, L. L. Kestin, et al., "Accelerated Partial Breast Irradiation Using 3D Conformal Radiation Therapy (3DCRT)," International Journal of Radiation Oncology* Biology*Physics, Vol. 55, No. 4, 2003, pp. 302-311. doi:10.1016/S0360-3016(02)03811-7

[22] S. C. Formenti, M. T. Truong, J. D. Goldberg, V. Mukhi, B. Rosenstein, D. Roses, et al., "Prone Accelerated Partial Breast Irradiation after Breast-Conserving Surgery: Preliminary Clinical Results and Dose-Volume Histogram Analysis," International Journal of Radiation Oncology* Biology*Physics, Vol. 60, No. 2, 2004, pp. 493-504. doi:10.1016/j.ijrobp.2004.04.036

[23] L. Livi, F. B. Buonamici, G. Simontacchi, V. Scotti, M. Fambrini, A. Compagnucci, et al., "Accelerated Partial Breast Irradiation with IMRT: New Tecnical Approach and Interim Analysis of Acute Toxicity in a Phase III Randomized Clinical Trial," International Journal of Radiation Oncology*Biology*Physics, Vol. 77, No. 2, 2010, pp. 509-515. doi:10.1016/j.jjrobp.2009.04.070

[24] J. V. Antonucci, M. Wallace, N. S. Goldstein, L. Kestin, P. Chen, P. Benitez, et al., "Differences in Patterns of Failure in Patients Treated with Accelerated Partial Breast Irradiation versus Whole-Breast Irradiation: A MatchedPair Analysis with 10-Year Follow-Up,” International Journal of Radiation Oncology*Biology*Physics, Vol. 74, No. 2, 2009, pp. 447-452.

doi:10.1016/j.ijrobp.2008.08.025

[25] B. Fisher, S. Anderson, J. Bryant, R. G. Margolese, M. Deutsch, E. R. Fisher, et al., "Twenty-Year Follow-Up of a Randomized Trial Comparing Total Mastectomy, Lumpectomy, and Lumpectomy plus Irradiation for the Treatment of Invasive Breast Cancer," New England Journal of Medicine, Vol. 347, No. 16, 2002, pp. 1233-1241. doi:10.1056/NEJMoa022152
[26] J. Fowler, “The Linear-Quadratic Formula and Progress in Fractionated Radiotherapy," British Journal of Radiology, Vol. 62, No. 740, 1989, pp. 679-694. doi:10.1259/0007-1285-62-740-679

[27] T. J. Whelan, J. P. Pignol, M. N. Levine, J. A. Julian, R. MacKenzie, S. Parpia, et al., "Long-Term Results of Hypofractionated Radiation Therapy for Breast Cancer," New England Journal of Medicine, Vol. 362, No. 6, 2010, pp. 513-520. doi:10.1056/NEJMoa0906260

[28] START Trialists’ Group, S. M. Bentzen, R. K. Agrawal, E. G. Aird, J. M. Barrett, P. J. Barrett-Lee, J. M. Bliss, J. Brown, J. A. Dewar, H. J. Dobbs, J. S. Haviland, P. J. Hoskin, P. Hopwood, P. A. Lawton, B. J. Magee, J. Mills, D. A. Morgan, J. R. Owen, S. Simmons, G. Sumo, M. A. Sydenham, K. Venables and J. R. Yarnold, "The UK Standardization of Breast Radiotherapy (START) Trial a of Radiotherapy Hypofractionation for Treatment of Early Breast Cancer: A Randomized Trial," Lancet Oncology, Vol. 9, No. 4, 2008, pp. 331-341. doi:10.1016/S1470-2045(08)70077-9

[29] START Trialists’ Group, S. M. Bentzen, R. K. Agrawal, E. G. Aird, J. M. Barrett, P. J. Barrett-Lee, S. M. Bentzen, J. M. Bliss, J. Brown, J. A. Dewar, H. J. Dobbs, J. S. Haviland, P. J. Hoskin, P. Hopwood, P. A. Lawton, B. J. Magee, J. Mills, D. A. Morgan, J. R. Owen, S. Simmons, G. Sumo, M. A. Sydenham, K. Venables, J. R. Yarnold, "The UK Standardization of Breast Radiotherapy (START) Trial B of Radiotherapy Hypofractionation for Treatment of Early Breast Cancer: A Randomized Trial," Lancet, Vol. 371, No. 9618, 2008, pp. 1098-1107. doi:10.1016/S0140-6736(08)60348-7

[30] L. Livi, M. Stefanacci, S. Scoccianti, D. Dicosmo, S. Borghesi, F. Nosi, et al., "Adjuvant Hypofractionated Radiation Therapy for Breast Cancer after Conserving Surgery," Clinical oncology (Royal College of Radiologists), Vol. 19, No. 2, 2007, pp. 120-124. doi:10.1016/j.clon.2006.11.006

[31] FAST Trialists Group, R. K. Agrawal, A. Alhasso, P. J. Barrett-Lee, J. M. Bliss, P. Bliss, D. Bloomfield, J. Bowen, A. M. Brunt, E. Donovan, M. Emson, A. Goodman, A. Harnett, J. S. Haviland, R. Kaggwa, J. P. Morden, A. Robinson, S. Simmons, A. Stewart, M. A. Sydenham, I. Syndikus, J. Tremlett, Y. Tsang, D. Wheatley, K. Venables and J. R. Yarnold, "First Results of the Randomised UK FAST Trial of Radiotherapy Hypofractionation for Treatment of Early Breast Cancer (CRUKE/ 04/015)," Radiotherapy and Oncology, Vol. 100, No. 1, 2011, pp. 93-100. doi:10.1016/j.radonc.2011.06.026

[32] S. Martin, M. Mannino, A. Rostom, D. Tait, E. Donovan, S. Eagle, et al., "Acute Toxicity and 2-Years Adverse Effects of 30 Gy in Five Fractions over 15 Days to Whole Breast after Local Excision of Early Breast Cancer," Clinical oncology (Royal College of Radiologists), Vol. 20, No. 7, 2008, pp. 502-505. doi:10.1016/j.clon.2008.04.020

[33] G. W. Barendsen, "Dose Fractionation, Dose Rate and Iso-Effect Relationship for Normal Tissue Responses," International Journal of Radiation Oncology*Biology* Physics, Vol. 8, 1982, pp. 1981-1997. doi:10.1016/0360-3016(82)90459-X 
[34] G. G. Steel, J. M. Deacon, G. M. Duchesne, A. Horwich, L. R. Kelland and J. H. Peacock, "The Dose-Rate Effect in Human Tumout Cells,” Radiotherapy and Oncology, Vol. 9, No. 4, 1987, pp. 299-310. doi:10.1016/S0167-8140(87)80151-2

[35] Y. Yamada, I. Ackerman, E. Franssen, R. G. MacKenzie and G. Thomas, "Does the Dose Fractionation Schedule Influence Local Control of Adjuvant Radiotherapy for Early-Stage Breast Cancer?” International Journal of Radiation Oncology*Biology*Physics, Vol. 44, No. 1, 1999, pp. 99-104. doi:10.1016/S0360-3016(98)00507-0

[36] H. D. Thames, S. M. Bentzen, I. Turesson, M. Overgaard and W. Van den Bogaert, "Time-Dose Factors in Radiotherapy: A Review of the Human Data," Radiotherapy and Oncology, Vol. 19, No. 3, 1990, pp. 219-235. doi:10.1016/0167-8140(90)90149-Q

[37] I. Turesson and H. D. Thames, "Repair Capacity and Kinetics of Human Skin during Fractionated Radiotherapy: Erythema, Desquamation, and Telangiectasia after 3 and 5 Year's Follow-Up," Radiotherapy and Oncology, Vol. 15, No. 2, 1989, pp. 169-188. doi:10.1016/0167-8140(89)90131-X

[38] J. O. Archambeau, R. Pezner and T. Wasserman, "Pathophysiology of Irradiated Skin and Breast,” International Journal of Radiation Oncology*Biology*Physics, Vol. 31, No. 5, 1995, pp. 1171-1185.

\section{doi:10.1016/0360-3016(94)00423-I}

[39] E. L. Travis and S. L. Tucker, "Isoeffect Models and Fractionated Radiation Therapy," International Journal of Radiation Oncology*Biology*Physics, Vol. 13, No. 2, 1987, pp. 283-287. doi:10.1016/0360-3016(87)90141-6

[40] R. G. Dale, “Time-Dependent Tumour Repopulation Factors in Linear-Quadratic Equation: Implication for Treatment Strategies,” Radiotherapy and Oncology, Vol. 15, No. 4, 1989, pp. 371-381. doi:10.1016/0167-8140(89)90084-4

[41] J. H. Matthews, B. E. Meeker and J. D. Chapman, "Response of Human Tumor Cell Lines in Vitro for Fractionated Radiation,” International Journal of Radiation Oncology*Biology*Physics, Vol. 16, 1989, pp. 133-138. doi:10.1016/0360-3016(89)90020-5

[42] P. D. Stanton, T. G. Cooke, G. Forster, D. Smith and J. J. Going, "Cell Kinetics in Vivo of Human Breast Cancer," British Journal of Surgery, Vol. 83, No. 1, 1996, pp. 98-102. doi:10.1002/bjs.1800830130

[43] K. Haustermans, J. Fowler, K. Geboes, M. R. Christiaens, A. Lerut and E. van der Schueren, "Relationshio between Potential Doubling Time (Tpot), Labeling Index and Duration of DNA Synthesis in 60 Esophageal and 35 Breast Tumors: Is It Worthwhile to Measure Tpot?” Radiotherapy and Oncology, Vol. 46, No. 2, 1989, pp. 157-167. doi:10.1016/S0167-8140(97)00164-3 